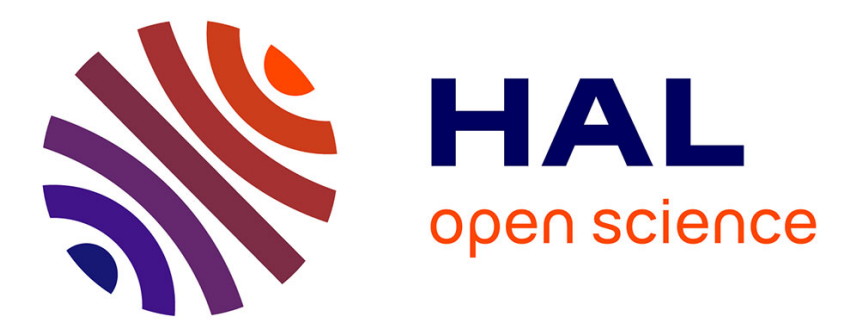

\title{
Preparation of YBa2Cu3O7 films by low pressure MOCVD using liquid solution sources
}

F. Weiss, K. Fröhlich, R. Haase, M. Labeau, D. Selbmann, J. Senateur, O. Thomas

\section{- To cite this version:}

F. Weiss, K. Fröhlich, R. Haase, M. Labeau, D. Selbmann, et al.. Preparation of YBa2Cu3O7 films by low pressure MOCVD using liquid solution sources. Journal de Physique IV Proceedings, 1993, 03 (C3), pp.C3-321-C3-328. 10.1051/jp4:1993344 . jpa-00251401

\section{HAL Id: jpa-00251401 https://hal.science/jpa-00251401}

Submitted on 1 Jan 1993

HAL is a multi-disciplinary open access archive for the deposit and dissemination of scientific research documents, whether they are published or not. The documents may come from teaching and research institutions in France or abroad, or from public or private research centers.
L'archive ouverte pluridisciplinaire HAL, est destinée au dépôt et à la diffusion de documents scientifiques de niveau recherche, publiés ou non, émanant des établissements d'enseignement et de recherche français ou étrangers, des laboratoires publics ou privés. 


\title{
Preparation of $\mathrm{YBa}_{2} \mathrm{Cu}_{3} \mathrm{O}_{7}$ films by low pressure MOCVD using liquid solution sources
}

F. WEISS, K. FRÖHLICH**, R. HAASE, M. LABEAU, D. SELBMANN* , J.P. SENATEUR and O. THOMAS

LMGP-ENSPG, CNRS URA 1109, BP. 46, 38402 Saint-Martin d'Hères, France

* I.F.W., Dresden, Helmolzstr. 20, 8027 Dresden, Germany

${ }^{* *}$ I.E.E., Slovak Academy of Sciences, Dubravska cesta 9, 84239 Bratislava, Czechoslovakia

\begin{abstract}
A hybrid low pressure MOCVD process is described for reproducible preparation of superconducting thin films of $\mathrm{YBa}_{2} \mathrm{Cu}_{3} \mathrm{O}_{7}$. The process uses a single solution source of $\mathrm{Y}, \mathrm{Ba}$, and $\mathrm{Cu} \beta$-diketonates dissolved in suitable organic solvents. This liquid precursor is atomized using an ultrasonic aerosol generator and transported as small droplets $(\approx 1 \mu \mathrm{m})$ into a CVD reactor where solvent and precursor are first evaporated before deposition takes place at low pressure on heated substrates in a cold wall geometry.

This process allows, with stable evaporation rates for all three precursors, to grow in-situ superconducting films with constant composition from film to film.

Thin and thick films with high critical temperatures and critical currents have been obtained (Tc>80K, Jc>104 $\mathrm{A} / \mathrm{cm}^{2}$ at $77 \mathrm{~K}$ in self field) which are highly c-axis oriented.

Experimental details of this new process are described and the effects of different process parameters are studied in order to improve the quality of the deposited layers.
\end{abstract}

\section{Introduction.}

Complex metal oxides can exhibit a variety of technologically useful properties, that can be exploited for a number of optical, electro-optical, microelectronic or superconducting applications. The fabrication of metal oxide ceramics with specific properties needs generally controlled chemical compositions and growth rates to produce high quality films or powders. For films growth with these characteristics two types of techniques are commonly used: the group of physical vapor deposition (PVD) techniques including sputtering, coevaporation, laser ablation... and the versatile class of methods represented by chemical vapor deposition (CVD) techniques. Over these, the potential advantages of CVD 
include the ability to deposit high quality, thick or ultrathin layers on three dimensional complex geometries and the amenability to large scale processing.

To date research in microelectronics or superconductivity is stimulated by the development of low temperature processes for the growth of epitaxial thin films. Nevertheless, the successful achievement of certain films by CVD is not straightforward and depends critically on the volatility and stability of the precursor materials which must be transformed into the product film.

Applying CVD to the High Temperature Superconductor (HTS) $\mathrm{YBa}_{2} \mathrm{Cu}_{3} \mathrm{O}_{7}$ is typical of this problem because of the lack of easily handled and stable precursors, particularly for the alkaline earth metal such as barium. Until recently, hydrocarbon based $\beta$-diketonate precursors such as $\mathrm{Ba}(\mathrm{dpm})_{2}$ (dpm=dipivalylmethanate; $\mathrm{C}_{11} \mathrm{H}_{19} \mathrm{O}_{2}$ ) have been used by several groups for in situ fabrication of HTS films by Metalorganic CVD (MOCVD) (1-5). Nevertheless, one of the major disadvantage of this precursor is that it must be heated in excess of $200^{\circ} \mathrm{C}$ to achieve sufficient volatility and that a extremely high control of temperature and gas mass flow is required to approach reproducible mass transport. Moreover, repeated thermal cycling near the melting temperature of $\mathrm{Ba}(\mathrm{dpm})_{2}$ results in decreased volatility of the source (presumably a consequence of oligomerization/decomposition processes). As a result, the compositional control and reproducibility of the film deposition process are often degraded.

Effective strategies to solve this problem should be to prepare new precursors with sufficient and stable volatility by encapsulation of the metal ion in a sterically saturating nonpolar environment or by ligand fluorination (6). Two alternative deposition routes are also developed today using the same principle based on source precursor separation and dispersion in order to prevent the source thermal decomposition over a long time. These two techniques are: flash evaporation of powder mixtures $(7,8)$, and evaporation of a sprayed solution where the metalorganic precursors are dissolved in a suitable solvent $(9,10)$. In the last case, experiences have been made generally at atmospheric pressure, but in order to promote in situ epitaxial growth and to reach deposition conditions close to those of a classical chemical vapor deposition process, the liquid source has to be first evaporated before deposition will take place at low pressure on heated substrates. The latter working conditions imply drastic conditions over the quality of the liquid source and the nature of the spray process used. In the present study we will present this new concept of low pressure single source aerosol CVD $(11,12)$ and we will discuss the use of liquid solution sources for the fabrication of complex metal oxide ceramic films. Emphasis will be placed on describing the physical and chemical processes which control the chemical composition and morphology of $\mathrm{YBa}_{2} \mathrm{Cu}_{3} \mathrm{O}_{7}$ layers produced by aerosol decomposition. Experimental details of this new process will be described and the problems to solve in order to optimize the quality of the deposited layers will be identified and discussed.

\section{Process description.}

The major difficulty encontered in CVD. processes is to work with precursors which have high enough vapor pressure and to prevent at any part of the reactor 
recondensation or prematurated reactions. This needs hot lines and eventually valves which make the CVD reactor expensive and difficult to operate.

Using an aerosol, the volatile precursors are dissolved in a suitable solvent and the solution is then drawn into a nebulizer and atomized. The mechanisms of deposition involved can be of different nature (sol-gel, CVD, powder deposition) depending on the process temperature and relative partial pressures of solvent and precursors in comparison with the working pressure. Different plausible mechanisms can be imagined between those extremes presented in figure 1.

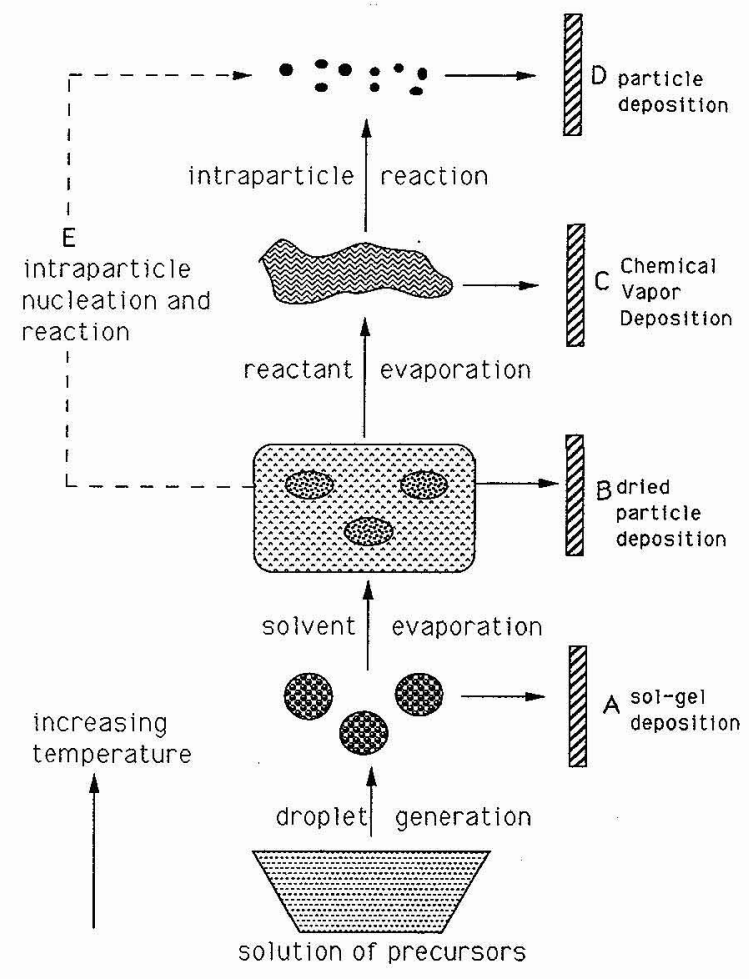

Figure 1: Schematic of the physicochemical processes involved during aerosol transport.

Several keys to perform layers in the CVD mode (process $C$ in figure 1) can be underlined.

The droplets which are formed have first to pass through a furnace, where the precursors and the solvent have to be evaporated in order to form the vapors of the individual metal complexes. This temperature must be just sufficient to vaporize totally the compounds, but has'nt to be critically controlled like in solid source evaporators used in conventional CVD.

Temperature and total vapor pressure into the preheated zone have to ensure a complete volatilization of the reacting species. For poorly volatile precursors, a decrease in the reactor total pressure helps to a good vaporization of precursors and prevents intraparticle nucleation and reactions (process $E$ in figure 1 ) which are detrimental for a high quality growth process. 
The solvent must nevertheless be judiciously chosen: unreactive with the precursor, completely evaporated at the temperature of the preheated zone and stable at room temperature under the working pressure.

Once the solvent and precursors are evaporated, the reaction dynamics are the same as in conventional MOCVD.

The advantages of this technique are: first its simplicity to operate, second the precursors solution remains at ambient temperature until the aerosol is injected in the heated zone, so that in principle thermally sensitive precursors may be used.

In a multicomponent system, single solution sources can be used to ensure a reproducible cationic ratio in the deposited layers.

\section{Experimental procedure for $\mathrm{YBa}_{2} \mathrm{Cu}_{3} \mathrm{O}_{7}$ deposition.}

The aforementioned principle has been applied to the synthesis of superconducting $\mathrm{YBa}_{2} \mathrm{Cu}_{3} \mathrm{O}_{7}$ layers. A schematic diagram of the single solution source MOCVD apparatus is given in figure 2.

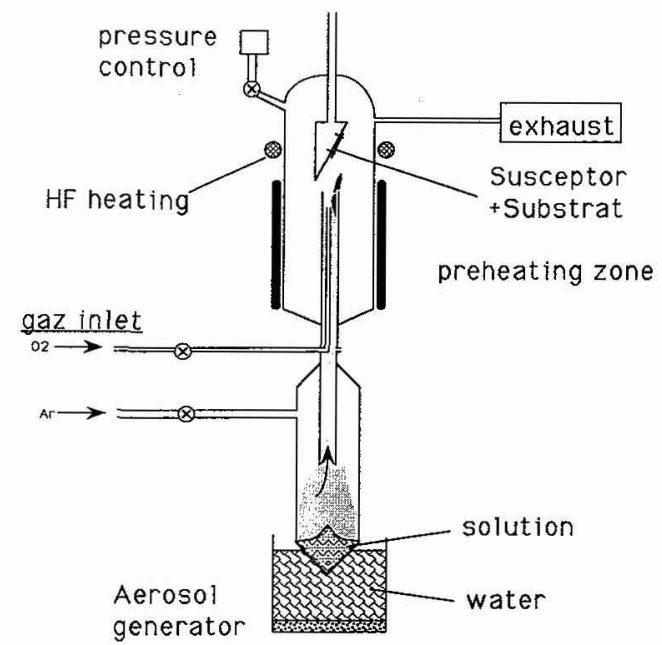

Figure 2: Schematic diagram of the low pressure MOCVD system using liquid solution sources.

The source solution was prepared by dissolving dpm complexes of $\mathrm{Y}, \mathrm{Ba}$ and $\mathrm{Cu}$ together in diethylene glycol dimethyl ether (diglyme). The concentration range can be varied up to $0.05 \mathrm{~mol} / \mathrm{l}$. Several other solvents can be used for this process (e.g. n-decane, n-dodecane, benzylalcohol..), they have to present as other characteristics a high boiling point at low pressure, good solubility for the source precursors and a convenient viscosity compatible with the nebulization system used. Furthermore organic solvent are often hygroscopic and special care has to be taken to use dry solvents in order to prevent precipitation during dissolution or a modification of the volatility of the precursors. 
As seen in figure 2 the aerosol is generated by a piezoelectric transducer at its resonance frequency (about $800 \mathrm{kHz}$ ) through the glass bottom of the reactor. This leads to the formation of a mist of microscopic droplets at the liquid surface which are transported by Argon as carrier gas through the preheating zone to the heated substrate. The film homogeneity and growth control are directly related to the ultrasonic pulverization method. The droplets have a medium diameter of a few microns (strongly dependent on the solvent partial pressure and viscosity) and a narrow size distribution contributing to an homogenous droplet evaporation with small residence times in the preheated zone $\left(250^{\circ} \mathrm{C}\right)$, avoiding solid phase reaction or precipitation.

After evaporation gases are mixed with oxygen and directed to the reaction zone where deposition occurs on single-cristalline $\mathrm{MgO}$ wafers. The deposition rates and kinetics are closely controlled by the quantity of precursors transported in unit time i.e. the product of the aerosol flow (monitored by the ultrasonic excitation power and carrier gas flow) and the precursor concentration in the liquid source yielding given partial pressures of reacting species in the gas phase after evaporation. Feed speeds from 0.1 to $1 \mathrm{ml} / \mathrm{min}$ were currently used.

Total pressure was kept at 10 torr and after a typical deposition time of 5 to $20 \mathrm{mn}$ samples were cooled down to room temperature in flowing oxygen during $30 \mathrm{mn}$.

Structural and physical characterisations of the deposited films include X-ray diffraction, SEM with EDAX for morphology, thickness and chemical analysis, temperature dependent a.c. resistivity $(8 \mathrm{~Hz}, 0.1 \mathrm{~mA})$, a.c. susceptibility $(800 \mathrm{~Hz}$, $20 \mathrm{mOe})$, pulsed critical current Jc measurements.

\section{Results and discussion.}

The synthesis of $\mathrm{YBa}_{2} \mathrm{Cu}_{3} \mathrm{O}_{7}$ layers has been studied by varying the different experimental parameters accessible in the present single source process. The growth rate of the films was found to be directly correlated to the precursor concentration in the starting solution, the ultrasonic power generated and the flow rate of Argon carrier gas. Growth rates as high as $10 \mu \mathrm{m} / \mathrm{h}$ can be attained. The deposition conditions for up to now the best superconducting films are as follows:

Source material

Composition ratio

of the solution

Concentration of solution

Mist feed rate

Preheated zone temperature

Flow rate of carrier gas ( $\mathrm{Ar}$ )

Flow rate of reactant gas $\left(\mathrm{O}_{2}\right)$

Total pressure

Deposition temperature

Deposition time

Substrate
$\mathrm{Y}, \mathrm{Cu}, \mathrm{Ba}, \mathrm{b}$-diketonates

dissolved in diglyme

$\mathrm{Y}: \mathrm{Ba}: \mathrm{Cu}=1: 2: 3$

$\mathrm{Y}: 0.007 \mathrm{~mol} / \mathrm{l}$

$0.2 \mathrm{ml} / \mathrm{min}$

$250^{\circ} \mathrm{C}$

$10 \mathrm{I} / \mathrm{h}$

$40 \mathrm{l} / \mathrm{h}$

10 torr

$870^{\circ} \mathrm{C}$

$10 \mathrm{mn}$

$\mathrm{MgO}(100)$ 
This film has a thickness of $0.6 \mu \mathrm{m}$ and its composition is slightly shifted against that of the starting solution. The analyzed value is: $\mathrm{Y}: \mathrm{Ba}: \mathrm{Cu}=1: 1.9: 4.3$.

Figure 3 shows the $x$-ray diffraction pattern corresponding to this sample. As indicated this film presents a strong c-axis texture with a Full Width at Half Maximum (FWHM) on the 006 diffraction peak of $0.3^{\circ}$ in two perpendicular directions.

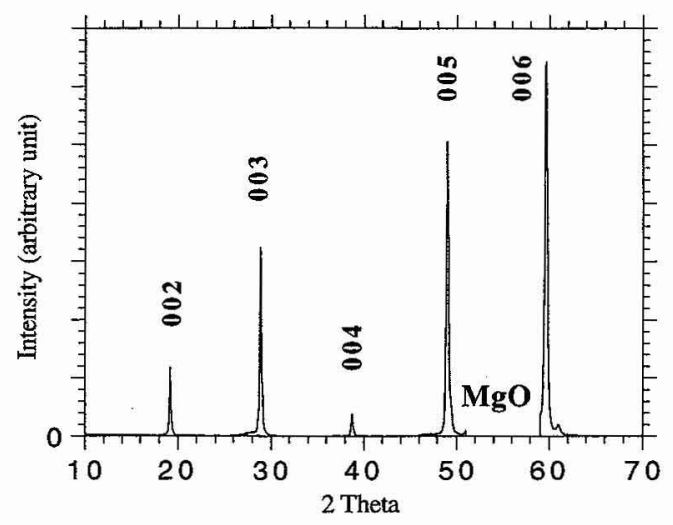

Figure 3: X-ray diffraction pattern of the $\mathrm{YBa}_{2} \mathrm{Cu}_{3} \mathrm{O}_{7}$ film deposited on $\mathrm{MgO}$ by single solution source MOCVD.

The temperature dependence of resistance for this film shows a metallic behaviour, but the high temperature part do not extrapolate to zero which seems to indicate a residual granularity (Figure 4). The residual resistivity $\rho_{100 \mathrm{~K}}=200 \mu \Omega . \mathrm{cm}$ is slightly higher than in the best samples obtained by conventional CVD. Nevertheless the transition to the superconducting state is relatively sharp and exhibits full transition at $T c_{R=0}=87 \mathrm{~K}$.

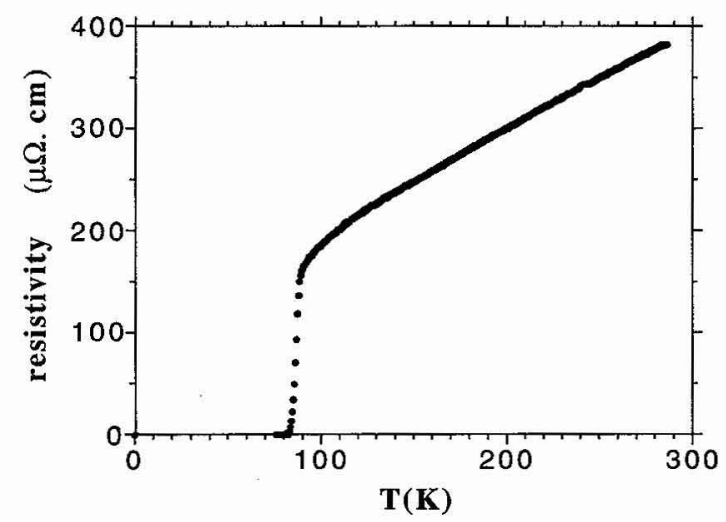

Figure 4: Temperature dependence of resistivity for the $0.6 \mu \mathrm{m}$ thick $\mathrm{YBa}_{2} \mathrm{Cu}_{3} \mathrm{O}_{7}$ film obtained by single solution source MOCVD. 
The critical current density value in self field at $77 \mathrm{~K}$ : Jc $=10^{4} \mathrm{~A} / \mathrm{cm}^{2}$, measured by a pulse technique on a $30 \mu \mathrm{m}$ large bridge patterned on the sample by conventional photolithography, has to be improved and seems to indicate the persistence of a granular behaviour, as seen also in the resistivity curve.

The fundamental difference existing between conventional CVD and this process, e.g. the presence of a great amount of solvent vapor during the reaction, can be one of the reason leading to the difficulty to reach high critical current values in the present process. Depending on the total pressure, nature of solvent and $\mathrm{O}_{2}$ to solvent vapor ratio, only a small part of the solvent is oxidized in spite of oxygen excess, but the exothermal effect of solvent vapor oxidation can be more or less pronounced and can change drastically the temperature conditions during deposition. In the case of diglyme this effect is quite low or inexisting and much less pronounced as for $n$-decane or $n$-dodecane (12). The presence of an excess of $\mathrm{CO}, \mathrm{CO}_{2}$ in the gas phase during deposition can also change significantly the thermodynamic equilibrium conditions for the synthesis of a pur $\mathrm{YBa}_{2} \mathrm{Cu}_{3} \mathrm{O}_{x}$ phase. As shown by Degterov et al.(13), the presence of $\mathrm{CO}_{2}$ in the gas phase reduces the stability field of $\mathrm{YBa}_{2} \mathrm{Cu}_{3} \mathrm{Ox}$, which is shifted to the high temperature region, and rises the tendency of $\mathrm{Ba}$ to form $\mathrm{BaCO}_{3}$. Carbonates formation at the sample surface can lead to the appearence of intergranular weak links and the observed granular behaviour. Carbon contamination can also play an essential role in the diffusion processes at the surface and can hinder the epitaxial grain growth or the oxygen diffusion during the oxidation step at the end of this process. These combined effects can result in non optimized single solution source MOCVD layers and in reduced critical currents in comparison with layers from conventional CVD.

\section{Conclusion.}

To improve today the quality of the $\mathrm{YBa}_{2} \mathrm{Cu}_{3} \mathrm{O}_{7}$ MOCVD layers obtained with single solution sources it appears that the choice of an appropriate solvent plays a crucial role. It must have a good solubility for $\mathrm{dpm}$ precursors, a low viscosity, low vapor pressure for convenient aerosol formation. The carbon content must also be low, in order to reduce the thermal instabilities due to solvent oxidation and to prevent carbonates formation or carbon contamination which can affect the superconducting properties.

\section{References.}

[1] F. Schmaderer, R. Huber, H. Oetzmann, G. Wahl

J. Phys IV 1 C2 (1991) 539

[2] J. Zhao, Y. Q. Li, C. S. Chern, P. Lu, P. Norris, B. Gallois, B. Kear, F. Cosandey, X. D. Wu, R. E. Muenchausen, S. M. Garrison Appl. Phys. Lett. 59 (10), 2 Sept. 1991, 1254 
[3] H. Yamane, M. Hasei, H. Kurosawa, T. Hirai

J.J.A.P. Vol. $30 \mathrm{~N}^{\circ}$ 6A, June 1991, L 1003

[4] O. Thomas, E. Mossang, J. Fick, F. Weiss, D. Boursier,R. Madar, J.P. Senateur, Physica C 185-189 (1991) 2113

[5] O. Yu Gorbenko, A.R. Kaul, Yu D. Tretyakov, V.I. Scritnii, S.A. Pozigun, V.A. Alekseev, Physica C 190 (1991) 180

[6] L.G. Hubert-Pfalzgraf et J.C. Daran, Appl. Organometal. Chem., 6 (1992) 627

[7] R. Hiskes, S.A. DiCarolis, R.D. Jacowitz, Z. Lu, R.S. Feigelson, R.K. Route, J.L. Young: Appl. Phys Lett. 59 (1991)606

[8] B. Schulte, M. Maul, W. Becker, S. Elschner, E.G. Schlosser, P. Haussler, H. Adrian, in "High Tc Superconducting Films" L. Correra ed., Elsvier publishers ISBN 444893539 (1992) 325

[9] S. Matsuno, F. Uchikawa, S. Ultsunomiya, Appl. Phys. Lett. 60(1992) 2427

[10] K.V. Salazar, K.C. Ott, R.C. Dye, K.M. Hubbart, E.J. Peterson, J.Y. Coulter, T.T. Kodas, Physica C 198 (1992) 303

[11] D. Selbmann, F. Weiss, E. Wolf, M. Labeau, J.P. Senateur German Patent N ${ }^{\circ}$ P 4138722.8

[12] W.Decker, Yu Erokin, O.Gorbenko, I.Graboy, A.Kaul, A.Nurnberg, M.Pulver R.Stolle, G. Wahl, Proc. E-MRS Meeting Strasbourg Nov.1993, to be published

[13] S.A.Degterov, Proc.Int.Worshop MSU-HTSCII; Moscow, Oct14-18(1991)142 